\title{
High non publication rate from publication professionals hinders evidence-based publication practices
}

Luke C Carey, Serina Stretton, Charlotte A Kenreigh, Linda T Wagner, Karen L Woolley

Background. The need for timely, ethical, and high-quality reporting of clinical trial results has seen a rise in demand for publication professionals. These publication experts, who are not ghostwriters, work with leading medical researchers and funders around the world to plan and prepare thousands of publications each year. Despite the involvement of publication professionals in an increasing number of peer-reviewed publications, especially those that affect patient care, there is limited evidence-based guidance in the peerreviewed literature on their publication practices. Similar to the push for editors and the peer-review community to conduct and publish research on publication ethics and the peer-review process, the International Society for Medical Publication Professionals (ISMPP) has encouraged members to conduct and publish research on publication planning and practices. Our primary objective was to investigate the publication rate of research presented at ISMPP Annual Meetings. Methods. ISMPP Annual Meeting abstract lists (April 2009 to April 2014) were searched in November 2014 and data were extracted into a pilottested spreadsheet. MEDLINE was searched in December 2014 to determine the publication rate (calculated as the $\%$ of presented abstracts published as full papers in peer-reviewed journals). Data were analyzed using the Cochran-Armitage trend test (significance: $P<.05$ ) by an independent academic statistician. Results. From 2009 to 2014, there were 220 abstracts submitted, 185 accepted, and 164 presented. There were four corresponding publications (publication rate 2.4\%). Over time, ISMPP's abstract acceptance rate (overall: $84.1 \%$ ) did not change, but the number of abstracts presented increased significantly $(P=.02)$. Most abstracts were presented as posters $(81.1 \%)$ and most research was observational (72.6\%). Most researchers came from the US (78.0\%), followed by Europe (17.7\%), and the Asia-Pacific region (11.2\%). Discussion. Research presented at ISMPP Annual Meetings has rarely been published in peer-reviewed journals. The high-rate of non publication by publication professionals has now been quantified and is of concern. Publication professionals should do more to contribute to evidence-based publication practices, including, and especially, their own. Unless the barriers to publication are identified and addressed, the practices of publication professionals, which affect thousands of peer-reviewed publications each year, will remain hidden and 
unproven. 


\section{ARTICLE TITLE}

2 High nonpublication rate from publication professionals hinders evidence-based publication

3 practices

5 AUTHORS

$6 \quad$ Luke C. Carey ${ }^{1}$

7 Stretton Stretton ${ }^{1}$

8 Charlotte A. Kenreigh ${ }^{2}$

9 Linda T. Wagner ${ }^{2}$

10 Karen L. Woolley ${ }^{1,3,4}$

12 AUTHORS' AFFILIATIONS

13 'ProScribe - Envision Pharma Group, Sydney, New South Wales, Australia

$14{ }^{2}$ Excel - Envision Pharma Group, Southport, Connecticut, USA

15 University of Queensland, Brisbane, Queensland, Australia

$16{ }^{4}$ University of the Sunshine Coast, Maroochydore DC, Queensland, Australia

18 AUTHOR FOR CORRESPONDENCE

19 Dr Luke Carey

20 ProScribe PTY Ltd., Suite 1.01

21 Talavera Business Park, Level 1, 6-10 Talavera Road

22 Macquarie Park NSW 2113, Australia 
23 Tel: +61397427069

24 Fax: +61 280584352

25 Email: luke.carey@envisionpharmagroup.com 


\section{ABSTRACT}

28 Background. The need for timely, ethical, and high-quality reporting of clinical trial results has

29 seen a rise in demand for publication professionals. These publication experts, who are not

30 ghostwriters, work with leading medical researchers and funders around the world to plan and

31 prepare thousands of publications each year. Despite the involvement of publication

32 professionals in an increasing number of peer-reviewed publications, especially those that affect

33 patient care, there is limited evidence-based guidance in the peer-reviewed literature on their

34 publication practices. Similar to the push for editors and the peer-review community to conduct

35 and publish research on publication ethics and the peer-review process, the International Society

36 for Medical Publication Professionals (ISMPP) has encouraged members to conduct and publish

37 research on publication planning and practices. Our primary objective was to investigate the

38 publication rate of research presented at ISMPP Annual Meetings.

39 Methods. ISMPP Annual Meeting abstract lists (April 2009 to April 2014) were searched in

40 November 2014 and data were extracted into a pilot-tested spreadsheet. MEDLINE was searched

41 in December 2014 to determine the publication rate (calculated as the $\%$ of presented abstracts

42 published as full papers in peer-reviewed journals). Data were analyzed using the Cochran-

43 Armitage trend test (significance: $P<.05$ ) by an independent academic statistician.

44 Results. From 2009 to 2014, there were 220 abstracts submitted, 185 accepted, and 164

45 presented. There were four corresponding publications (publication rate 2.4\%). Over time,

46 ISMPP's abstract acceptance rate (overall: $84.1 \%$ ) did not change, but the number of abstracts

47 presented increased significantly $(P=.02)$. Most abstracts were presented as posters $(81.1 \%)$ and 
48 most research was observational (72.6\%). Most researchers came from the US (78.0\%), followed 49 by Europe (17.7\%), and the Asia-Pacific region (11.2\%).

50 Discussion. Research presented at ISMPP Annual Meetings has rarely been published in peer-

51 reviewed journals. The high-rate of nonpublication by publication professionals has now been

52 quantified and is of concern. Publication professionals should do more to contribute to

53 evidence-based publication practices, including, and especially, their own. Unless the barriers to

54 publication are identified and addressed, the practices of publication professionals, which affect

55 thousands of peer-reviewed publications each year, will remain hidden and unproven. 


\section{INTRODUCTION}

59 Rennie and Flanagin warned that the quest to improve publication practices requires “...a

60 massive and prolonged effort on the part of researchers, funders, institutions, and journal

61 editors..." (Rennie \& Flanagin, 2014). Fundamental to this quest is research on publication

62 practices. Such research should address important questions, be well-designed, conducted, and

63 published - in full; published abstracts are insufficient to inform practice (Hopewell et al., 2008).

64 Conducting and publishing research on publication practices, however, isn't easy, even for

65 editors and the peer-review community (Rennie \& Flanagin, 2014). Malički and colleagues

66 reported that “...39\% of research presented at Peer Review and Biomedical Publication (PRC)

67 congresses had not been fully published..." based on an analysis of the seven congresses from

681989 to 2013 (Malički, von Elm \& Marušic, 2014).

Publication professionals work with researchers and funders around the world to plan and

71 prepare thousands of publications each year (Wager et al., 2014) and have a responsibility to join

72 the research effort. These experts, who are not ghostwriters, must shine an empirical light on the

73 integrity and effectiveness of their practices as these practices affect the quality and currency of

74 the medical literature that influences patient care. Unless publication professionals publish their

75 research results in peer-reviewed journals, much of what they do remains hidden.

77 The International Society for Medical Publication Professionals (ISMPP), a not-for-profit association with $>1,400$ members, has a mission to "advance the medical publication profession

79 globally through enhanced integrity and transparency in medical publications, improved 
80 standards and best practices, and education, advocacy, and professional collaborations"

81 (http://www.ismpp.org/mission-and-vision). Similar to the analyses of research presented at PRCs

82 (Malički, von Elm \& Marušic, 2014), we investigated the publication rate of research presented

83 at ISMPP Annual Meetings. 


\section{MATERIALS AND METHODS}

86 This was a retrospective cohort study of ISMPP Annual Meeting abstracts (April 2009 to April

87 2014).

88

89 Abstract metrics and data were obtained from Current Medical Research and Opinion (CMRO)

90 Supplements (2009 onwards) and verified against ISMPP records. Submission and acceptance

91 data were obtained from ISMPP. Corresponding full-text publications were identified by

92 searching (17 December 2014) MEDLINE using the first, second, or last author surname and key

93 terms from the title.

94

95 Abstracts were categorized based on author affiliations and study type. Publication rate was

96 calculated as the percentage of presented abstracts published as full-text publications in peer-

97 reviewed journals. Data were analyzed by Cochran Armitage trend test. Differences in

98 acceptance rate, abstracts published, study type, and contributor affiliations were considered

99 significant at $P<.05$. 


\section{RESULTS}

102 Of 220 abstracts submitted to ISMPP Annual Meetings, 185 (84.1\%) were accepted for

103 presentation; of these, $164(88.6 \%)$ were published in $C M R O$. Almost all of the research

104 presented at ISMPP was never published in full in peer-reviewed journals; the publication rate

105 was $2.4 \%$ (4/164; Fig. 1). Of the 4 research abstracts subsequently published as full papers, only

1061 had been selected by ISMPP for an oral presentation (Table 1). The four publications were

107 authored by 11 individuals who had advanced degrees ( $\mathrm{PhD}$ or medical degree). Of these 11 ,

108 eight were also Certified Medical Publication Professionals, signifying that they had passed an

109 international exam on publication ethics and practices. All the authors worked as publication

110 professional employees in medical communication or biopharmaceutical companies and, on

111 average, had 20 peer-reviewed publications each.

112

113 Most abstracts were presented as posters $(133 / 164 ; 81.1 \%)$. The remaining abstracts were,

114 therefore, selected for oral presentations (ie, 31/164; 18.9\%). Abstracts described mainly

115 observational $(119 / 164 ; 72.6 \%)$ or opinion-based $(37 / 164 ; 22.6 \%)$ research; interventional

116 research was rare $(6 / 164 ; 3.7 \%)$. Over time, the number of abstracts in $C M R O$ increased

117 significantly (15 in 2009 to 36 in 2014; $P=.02)$; there were no changes in acceptance rate $(P=$

118.44 ) or study type (observational $P=.52$, interventional $P=.62$, opinion $P=.82$ ). Abstracts were

119 submitted by researchers from the US (453/581; 78.0\%), Europe (103/581; 17.7\%), and the Asia-

120 Pacific region $(65 / 581 ; 11.2 \%)$. Most research was conducted by medical communication

121 agencies $(91 / 164 ; 55.5 \%)$, rather than healthcare companies $(38 / 164 ; 23.2 \%)$. 


\section{DISCUSSION AND CONCLUSIONS}

124 Research from ISMPP Annual Meetings has rarely been published in peer-reviewed journals.

125 The publication rate $(2.4 \%)$ is approximately 25 -fold lower compared with research presented at 126 biomedical conferences (55.9\%) (Scherer et al., 2015) and PRCs (60.5\%) (Malički, von Elm \& 127 Marušic, 2014) (Fig. 1).

128

129 For publication professionals to join editors and the peer-review community in the quest to drive 130 evidence-based improvements in publication practices (Rennie \& Flanagin, 2014), they need to

131 "practice what they preach" (ie, design, conduct, and publish meaningful and robust research).

132 Doing so would help the broader research community in its quest to improve publication

133 practices and enable Good Publication Practice guidelines (Battisti et al., 2015), which many

134 publication professionals follow (Wager et al., 2014), to be based on evidence, rather than expert 135 opinion.

137 Our study has quantified, for the first time, the extent of nonpublication by publication

138 professionals. Additional studies, ideally with qualitative research methods, will be required to

139 investigate the reasons for the low publication rate. We speculate that lack of time may be one of

140 the main drivers for nonpublication. A systematic review, which investigated the reasons why

141 biomedical researchers don't publish, reported that lack of time was the most frequent, as well as

142 the most important, reason provided for nonpublication (Scherer et al., 2015). In our experience,

143 most publication professionals are not employed to design, conduct, and publish research on

144 publication practices. Such research is likely to depend on considerable "after hours" time.

145 Additional reasons may include lack of resources (eg, limited funding to gain expert support 
146 from statisticians and professional medical writers), competing priorities (eg, professional duties,

147 personal responsibilities), and uncertainty regarding the most important and feasible research

148 projects to pursue. We also recognize that publication professionals may conduct the type of

149 research (eg, surveys and descriptive analyses on operational issues) that may not be appropriate

150 nor robust enough for the peer-reviewed literature.

151

152 Our study has limitations (including focusing on ISMPP Annual Meetings). As our intent was to

153 investigate how well publication professionals contribute to the evidence base affecting

154 publication practices, we focused on the largest annual meeting for publication professionals. We

155 recognize that publication professionals may attend other meetings, but these meetings may not

156 be focused primarily on publication practices, may not have dedicated sessions for research-

157 based presentations from publication professionals, and may not have been held as consistently

158 or for as long as the ISMPP has held annual meetings. Our study is also limited by the focus on

159 peer-reviewed publications included in the MEDLINE database (up until December 2014). We

160 recognize that peer-reviewed publications may have appeared in other databases and after we

161 conducted our search. We focused on MEDLINE because it was readily accessible and is one of

162 the largest databases for medical research articles. We reasoned that those with an interest in

163 medical research publication practices would search MEDLINE for relevant peer-reviewed

164 articles.

165

166 In summary, the publication rate from research presented at ISMPP Annual Meetings is low.

167 Publication professionals, who plan and prepare thousands of peer reviewed publications each 
168 year, should do more to contribute to evidence based publication practices, including, and 169 especially, their own. 


\section{ACKNOWLEDGMENTS}

172 These findings were presented at the $11^{\text {th }}$ Annual Meeting of the International Society for

173 Medical Publication Professionals, 27-29 April 2015, Arlington, VA, USA. 


\section{REFERENCES}

175 Battisti WP, Wager E, Baltzer L, Bridges D, Cairns A, Carswell CI, Citrome L, Gurr JA,

176 Mooney LA, Moore BJ, Peña T, Sanes-Miller CH, Veitch K, Woolley KL, Yarker YE. 2015.

177 Good Publication Practice for Communicating Company-Sponsored Medical Research: GPP3.

178 Annals of Internal Medicine 163:461-464. DOI: 10.7326/M15-0288.

179

180 Hopewell S, Clarke M, Moher D, Wager E, Middleton P, Altman DG, Schulz KF; CONSORT

181 Group. 2008. CONSORT for reporting randomised trials in journal and conference abstracts.

182 Lancet 371:281-283. DOI: 10.1016/S0140-6736(07)61835-2.

183

184 Malički M, von Elm E, Marušic A. 2014. Study design, publication outcome, and funding of 185 research presented at international congresses on peer review and biomedical publication. The 186 Journal of the American Medical Association 311:1065-1067. DOI: 10.1001/jama.2014.143.

188 Rennie D, Flanagin A. 2014. Research on peer review and biomedical publication: furthering the 189 quest to improve the quality of reporting. The Journal of the American Medical Association 190 311:1019-1020. DOI: 10.1001/jama.2014.1362.

191

192 Scherer RW, Ugarte-Gil C, Schmucker C, Meerpohl JJ. 2015. Authors report lack of time as

193 main reason for unpublished research presented at biomedical conferences: a systematic review.

194 Journal of Clinical Epidemiology 68:803-810. DOI: 10.1016/j.jclinepi.2015.01.027. 195 
196 Wager E, Woolley K, Adshead V, Cairns A, Fullam J, Gonzalez J, Grant T, Tortell S. 2014.

197 Awareness and enforcement of guidelines for publishing industry-sponsored medical research

198 among publication professionals: the Global Publication Survey. British Medical Journal Open.

199 4:e004780. DOI: 10.1136/bmjopen-2013-004780.

200 
201 Table 1. Four research studies presented at ISMPP Annual Meetings that were published in peer-

202 reviewed journals

\begin{tabular}{|c|c|c|c|c|}
\hline $\begin{array}{l}\text { ISMPP } \\
\text { Annual } \\
\text { Meeting }\end{array}$ & $\begin{array}{c}\text { ISMPP } \\
\text { decision on } \\
\text { type of } \\
\text { presentation }\end{array}$ & Research topic & $\begin{array}{l}\text { MEDLINE- } \\
\text { listed journal } \\
\text { the published } \\
\text { the research }\end{array}$ & $\begin{array}{c}\text { Time from } \\
\text { presentation } \\
\text { to } \\
\text { publication } \\
\text { (months) }\end{array}$ \\
\hline 2010 & Oral & $\begin{array}{l}\text { Lack of involvement } \\
\text { of medical writers and } \\
\text { the pharmaceutical } \\
\text { industry in } \\
\text { publications retracted } \\
\text { for misconduct: a } \\
\text { systematic, controlled, } \\
\text { retrospective study. }\end{array}$ & $\begin{array}{c}\text { Current } \\
\text { Medical } \\
\text { Research and } \\
\text { Opinion }\end{array}$ & 14 \\
\hline 2011 & Poster & $\begin{array}{l}\text { Publication } \\
\text { misconduct and } \\
\text { plagiarism retractions: } \\
\text { a systematic, } \\
\text { retrospective study. }\end{array}$ & $\begin{array}{c}\text { Current } \\
\text { Medical } \\
\text { Research and } \\
\text { Opinion }\end{array}$ & 18 \\
\hline 2012 & Poster & $\begin{array}{l}\text { Systematic review on } \\
\text { the primary and } \\
\text { secondary reporting of } \\
\text { the prevalence of } \\
\text { ghostwriting in the } \\
\text { medical literature. }\end{array}$ & BMJ Open & 27 \\
\hline 2013 & Poster & $\begin{array}{l}\text { Sponsor-imposed } \\
\text { publication } \\
\text { restrictions disclosed } \\
\text { on ClinicalTrials.gov. }\end{array}$ & $\begin{array}{l}\text { Accountability } \\
\text { in Research }\end{array}$ & 15 \\
\hline
\end{tabular}

Abbreviation: ISMPP, International Society for Medical Publication Professionals. 


\section{FIGURE LEGEND}

206

207 Figure 1. Low publication rates from ISMPP Annual Meetings versus publication rates from

208 biomedical conferences (Scherer et al., 2015) and Peer Review Congresses (Malički, von Elm \&

209 Marušic, 2014). Abbreviation: ISMPP, International Society for Medical Publication

210 Professionals. 


\section{Figure 1}

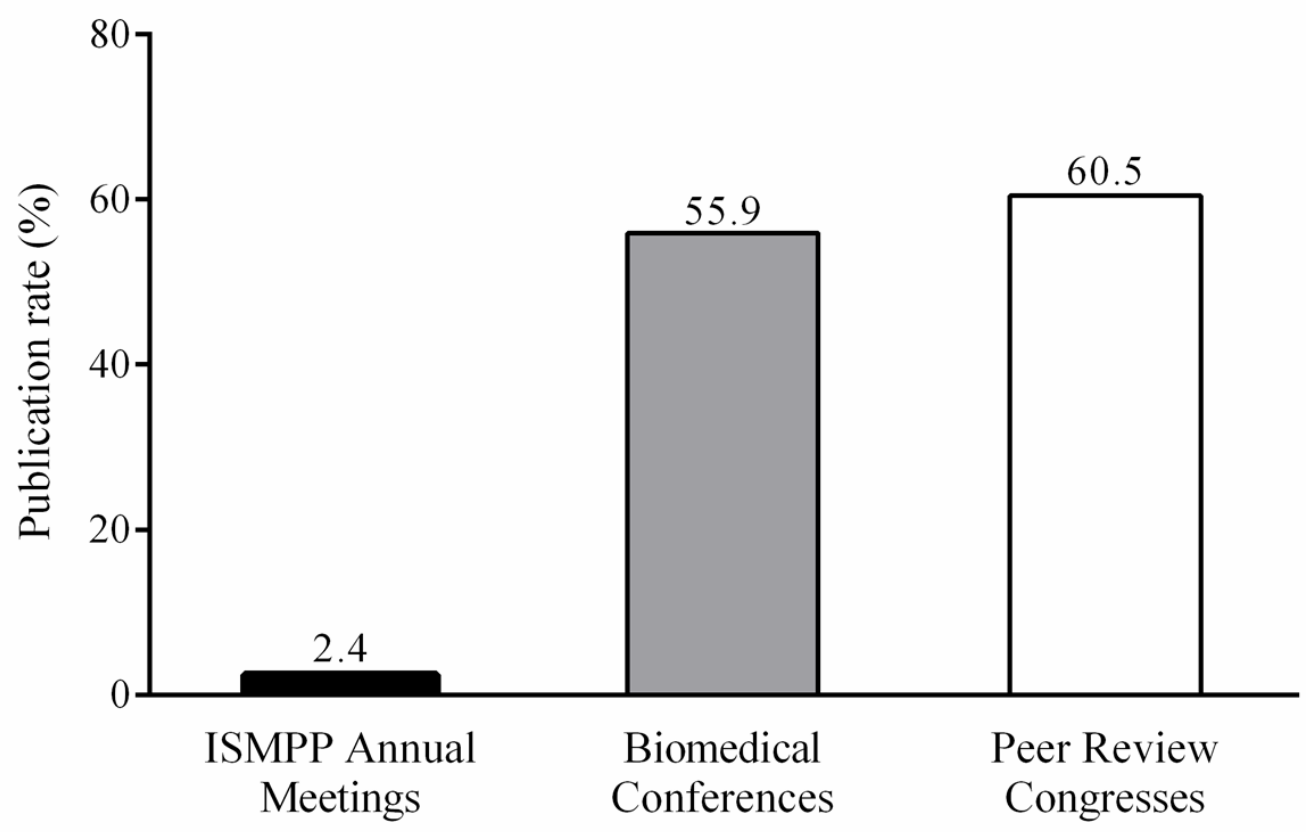

212 